\title{
The relationships between parents' and children's screen times on weight status: A cross-sectional path analysis
}

Kaori Ishii ( $\square$ ishiikaori@waseda.jp)

Waseda University

Ai Shibata

University of Tsukuba

Mohammad Javad Koohsari

Waseda University

Koichiro Oka

Waseda University

\section{Research Article}

Keywords: sedentary behavior, elementary school children, sitting, community-based, Japan

Posted Date: February 16th, 2022

DOI: https://doi.org/10.21203/rs.3.rs-1333235/v1

License: (a) (1) This work is licensed under a Creative Commons Attribution 4.0 International License.

Read Full License 


\section{Abstract}

Background: Understanding factors that contribute to an individual reducing his/her screen time is important for promoting a healthy weight. Parents' and guardians' behavior affects children as they influence their daily decision-making through modeling, rules or restrictions, social support, and coparticipation. The present study examined how the direct and indirect effects of parents' and children's behaviors regarding screen time influenced body mass index among Japanese elementary school children.

Methods: The participants included 283 Japanese children aged 6-12 years who were randomly selected from resident registries of two cities. Screen time and sociodemographic attributes, including gender, age, employment status, height, and weight, were assessed using a mail-based survey. Path analyses were conducted to determine associations among children's, fathers', and mothers' variables. It was hypothesized that after controlling for household income and children's sex and age, mothers' and fathers' screen time on weekdays and at the weekend would be related to children's weekday and weekend screen time, respectively. In addition, the present study hypothesized that children's weekday and weekend screen time was related to children's weight status.

Results: Both fathers' and mothers' weekday screen times were associated with children's weekday and weekend screen times. Body mass index was affected by children's weekday screen time (0.117). The path coefficients for the indirect effects of mothers' and fathers' screen time on children's body mass index through children's weekday screen time was 0.016 from the fathers' weekday screen time and 0.024 from the mothers' weekday screen time (goodness-of-fit statistic $=.980$, adjusted goodness-of-fit statistic $=.953$, root mean square error of approximation $=.030$, Akaike information criterion $=93.030$ ).

Conclusions: The present study indicated that both fathers' and mothers' weekday screen times had indirect effects on children's weight status through children's weekday screen time among Japanese elementary school children. The strongest indirect effects could be seen by examining the paths of a mother's weekday screen time through children's screen time to weight status. The findings imply that intervention strategies to reduce screen time in children should focus on modeling of the mothers' behavior.

\section{Background}

Obesity in children is a public concern worldwide and is associated with type 2 diabetes, hypertension, and an increased risk of obesity in adulthood [1,2]. For example, in Japan, $11.1 \%$ of boys and $8.8 \%$ of girls aged 11 years were classified as obese in 2019 [3]. Compared to other developed countries, levels of obesity in Japanese children are low [4]; however, the percentage has grown in the last 10 years [3]. Therefore, prevention of obesity in children is important for their future health.

Excessive sedentary behavior is associated with poor health and can result in increased adiposity, worse cardiometabolic health and fitness, impaired behavioral conduct/pro-social behavior, and reduced sleep 
duration [5]. For children, several current physical activity guidelines [6,7] recommend recreational screen time of no more than $2 \mathrm{~h}$ per day (i.e., watching television [TV], digital video discs, or videos, playing TV games, or using computers or the internet) and avoiding prolonged periods of sitting. Nevertheless, children are spending too much time sitting in their recreational screen time worldwide [8]. For instance, in the United States, $66 \%$ of children spend at least $2 \mathrm{~h}$ of screen time per day [9]. In Japan, approximately $60 \%$ of children have been found to exceed the $2 \mathrm{~h}$ per day mark of screen time [10].

Parents play an important role in children's daily decision making through modeling, rules or restrictions, social support, and co-participation [11,12]. Previous review studies have shown that parents' screen time is positively correlated with children's screen time [13-27], and co-viewing with parents has been associated with increased screen time in children [28,29]. Moreover, the impact on children's screen time appears to be dependent on the sex of the guardian, as a previous study reported that mothers' screenbased behaviors showed a positive correlation with children's screen time $[17,28,29]$. However, few studies have considered gender differences in parental roles. Studies that have examined both the father's and mother's influence on children's sedentary behavior report that compared to the father's sedentary behavior, the mother's sedentary behavior influences the child's sedentary behavior more [28,29]. Xu et al. [30] concluded that reducing parents' screen time could decrease the screen time of their child. Therefore, it is necessary to examine the impact of both fathers' and mothers' screen time on children.

In addition to the influence of the parents' gender, it has been reported that the influence of the parents' screen time on children's screen time varies between weekdays and weekends [19,27]. Jago et al. (2014) [27] concluded that associations observed between parent and child screen-viewing were different between weekdays and the weekend; they showed that for a weekday, children were 3.4 times more likely to exceed $2 \mathrm{~h}$ of screen viewing if their father watched TV for at least $2 \mathrm{~h}$ per day, while for a weekend day, children were 4.8 times more likely. There were similar associations for mothers; children were 3.7 times more likely to exceed $2 \mathrm{~h}$ of screen viewing if their mother watched TV for at least $2 \mathrm{~h}$ per day for a weekday, while children were 4.7 times more likely for a weekend. However, to our knowledge, only a few studies have examined this differentiation between the weekdays and weekends.

The indirect effects and the strength of paternal and maternal screen time on children's screen time and body mass index (BMI) have not been examined, although there are studies that have examined each of these variables directly, such as parents' screen time and children's screen time [13-30], or children's screen time and BMI [5]. Considering the impact of the behaviors of both father and mother on children in real life, parental behaviors may impact children's screen time and BMI, and suggestions for specific interventions to improve children's health might be possible through research. Thus, the present study examined how the direct and indirect effects of parents' and children's screen time behaviors influenced children's BMI among Japanese elementary school children.

\section{Methods}

\section{Participants and data collection}


The present cross-sectional study was conducted in a cohort of children living in Musashino City, Japan, in 2018 and Kokubunji City, Japan, in 2017. A total of 4,800 potential residents aged 6-12 years were randomly selected from the residential registries of their respective cities. Both Musashino (population: 150,660 in October 2021) and Kokubunji (population: 130,636 in October 2021) are cities in Tokyo, Japan. Potential participants were stratified by sex (boys/girls) and school grade ( $1^{\text {st }}$ grade: $6-7$ years,

$2^{\text {nd }}$ grade: $7-8$ years, $3^{\text {rd }}$ grade: $8-9$ years, $4^{\text {th }}$ grade: $9-10$ years, $5^{\text {th }}$ grade: $10-11$ years, and $6^{\text {th }}$ grade: 11-12 years). First, invitation letters explaining the study were sent to all potential participants. A questionnaire and accelerometer were sent to those who responded to the invitation letter indicating that they were willing to participate. To encourage a response, potential participants were told that a 1,000-yen book voucher would be offered to those who returned the questionnaire and accelerometer. Nonrespondents were sent one reminder about the responses to a questionnaire and accelerometer. A total of 1,772 individuals (36.9\% overall response rate; 881 responders [36.7\%] from Musashino and 891 responders [37.1\%] from Kokubunji) responded to the invitation. Then, self-administered questionnaires, which included questions about sociodemographic variables, screen time, and children's height and weight, were mailed to those who responded that they would be willing to participate (620 individuals; $12.9 \%$ of those who said they would be willing to participate, 310 people in each city). A total of 484 individuals completed both the questionnaire and accelerometer measurements $(78.1 \%$ overall response rate; $81.0 \%$ from Musashino, and $71.3 \%$ from Kokubunji). Data from 283 children, mothers, and fathers who fully completed both questionnaires were included in the analysis. Participation was voluntary, and confidentiality was ensured. A previous study [31] suggested that children younger than 10 years of age are unable to report their activity patterns accurately or reliably. Alternatively, parental reports of physical activity among 6-year-olds have been shown to strongly correlate with heart rate measures during physical activity [32]. Therefore, parents or guardians of the children were asked to complete the questionnaire with their children.

\section{Standard protocol approvals, registrations, and patient consent}

All children, mother, and father signed an informed consent form before answering the questionnaire. The Ethics Committee of Waseda University, Japan, approved the study prior to its commencement (2017245). The present study was conducted in accordance with the principles of the 2013 Declaration of Helsinki.

\section{Measures}

\section{Self-reported screen time}


Domain-specific sedentary behaviors were assessed using a questionnaire. For children, sedentary behavior was divided into six domains [10] (1) reading or listening to music, (2) TV or video viewing, (3) TV game use, (4) internet or e-mail (computer or tablet) use outside of class, (5) doing homework or assignments, and (6) car travel for transport. Participants were asked how many days on average per week and how much time (hours and minutes) on average per day they engaged in these sedentary behaviors during weekdays and weekends in each domain. Then the frequency per week was multiplied by the number of minutes per day. Each domain-specific sedentary behavior was examined separately, and we calculated the average total number of minutes for each school week (Monday-Friday) and weekends (days $\times$ minutes per day). Screen time was calculated using the total of domains (2), (3), and (4). The mothers and fathers were asked to report daily average sedentary time (hours and minutes) over the past 7 days, separately for workdays (weekdays for non-employed) and non-workdays (weekend for non-employed) across the following six domains: (1) being transported to and from a place by car; (2) using public transport; (3) at work; (4) watching television, videos, and DVDs; (5) using a computer, cell phone, and tablet PC outside of working hours; and (6) during leisure time (excluding watching television, videos, and DVDs) [33]. The total minutes of daily average screen time was calculated by summing (4) and (5), separately for workdays and non-workdays. Average daily values of sedentary time were calculated with weighting to account for the number of weekdays and weekend days.

\section{Sociodemographic factors}

Data on children's age and sex were collected from the residential registries. The children's weights and heights were obtained from the questionnaire responses. BMI was calculated from the height and weight data (BMI = weight/height [2]). Children's BMI percentiles were calculated using the metric system of the Centers for Disease Control and Prevention [34]. Children were classified according to the recommended BMI-for-age cutoffs [34]: $<5$ th percentile, underweight; $5-85^{\text {th }}$ percentile, normal BMl; and $\geq 85^{\text {th }}$ percentile, overweight or obese. Additionally, household income level per year $(<3, \geq 3-<5, \geq 5-<7, \geq 7-$ $<10$, or $\geq 10$ million yen) was assessed from parents or guardians.

\section{Statistical analyses}

The data analysis involved assessing the replies from the 283 children, fathers, and mothers who had fully responded. Path analyses were conducted to determine the presence of any associations between the children's, fathers', and mothers' variables. It was hypothesized that after controlling for household income and children's sex and age, mothers' and fathers' screen time during the weekdays and the weekend would be related to children's screen time during the weekdays and the weekend, respectively; it was also hypothesized that children's weekday and weekend screen time would be related to BMI. Path coefficients and correlations are reported as standardized estimates. The model was assessed using the goodness-of-fit statistic (GFI), adjusted goodness-of-fit statistic (AGFI), root mean square error of approximation (RMSEA), and Akaike information criterion (AIC). GFI and AGFI indices were used to 
measure how well the model fit the data. Values of 0.90 or greater indicated a good model fit [35]. RMSEA is a measure of the descriptive measures of overall model fit. An RMSEA score values lower than 0.05 indicated a good fit [36]. A lower AIC value for a model indicated a better fit than the other models [37]. A model was considered to fit the data well when the following criteria were met: GFI $>0.90$, AGFI $>0.90$, RMSEA $<0.06$, and a lower AIC value compared with competing models. Statistical significance was set at $p<0.05$. The data were analyzed using path analyses estimated using IBM SPSS AMOS 27.0J for Windows (IBM Corp., Armonk, N.Y., USA).

\section{Results}

\section{Demographics and screen time of the participants}

A total of 283 Japanese children and their guardians (127 boys and 156 girls; 144 in Musashino and 139 in Kokubunji) completed the survey. Table 1 shows the demographic characteristics of the participants and their screen time during the weekdays and weekends. The children's mean (standard deviation) age was 8.7 (1.7) years old, and $82.3 \%$ of children had a healthy weight status. Regarding socioeconomic status, $41.7 \%$ of families had a household income of $\geq 10,000,000$ yen. The child's, mother's, and father's mean screen time were 112.5 (92.1), 148.1 (112.4), and 123.1 (86.6) on weekdays, and 155.4 (102.1), 167.5 (108.3), and 212.9 (134.8) on weekends, respectively. 
Table 1

Descriptive characteristics (numbers and percentages)

\begin{tabular}{llll} 
& Variables & $\mathrm{n}$ & $\%$ \\
\hline \multicolumn{1}{l}{ Overall } & 283 & 100.0 \\
\hline Sex & & & \\
\hline \multicolumn{1}{l}{ Boys } & 127 & 44.9 \\
\hline Girls & 156 & 55.1 \\
\hline Age, group & & \\
\hline 6 years & 18 & 6.4 \\
\hline 7 years & 61 & 21.6 \\
\hline 8 years & 69 & 24.4 \\
\hline 9 years & 49 & 17.3 \\
\hline 10 years & 38 & 13.4 \\
\hline 11 years & 29 & 10.2 \\
\hline 12 years & 19 & 6.7 \\
\hline Mean \pm SD & $8.7 \pm 1.7$
\end{tabular}

BMI percentile for age and sex

$\begin{array}{lll}\text { Underweight (<5th \%ile) } & 21 & 7.4\end{array}$

Normal BMI (5th - 85th \%ile) $\quad 233 \quad 82.3$

Overweight or obese ( $\geq 85$ th \%ile) $\quad 29 \quad 10.2$

Household income level

\begin{tabular}{ccc}
\hline$<3,000,000$ yen & 3 & 1.1 \\
\hline$<5,000,000$ yen & 26 & 9.2 \\
$<7,000,000$ yen & 41 & 14.5 \\
\hline$<10,000,000$ yen & 95 & 33.6 \\
\hline$\geq 10,000,000$ yen & 118 & 41.7 \\
\hline Screen time-weekday, min/day, Mean \pm SD & & \\
\hline Children & $112.5 \pm 92.1$ \\
\hline Mothers & $148.1 \pm 112.4$ \\
\hline
\end{tabular}


Screen time-weekend, min/day, Mean \pm SD

Children

$155.4 \pm 102.1$

Mothers

$167.5 \pm 108.3$

Fathers

$212.9 \pm 134.8$

Abbreviations: BMI, body mass index; SD, standard deviation

\section{Direct and indirect effects of parents' and children's screen time behaviors on BMI}

Fig. 1 shows the direct and indirect relationships between weekday and weekend mothers' and fathers' screen time, children's weekday and weekend screen time, and BMI. All path coefficients are standard partial regression coefficients. With the standard partial regression coefficients, the magnitude of each factor can be directly compared with the other factors in the model.

The present study identified no significant associations between (1) fathers' or mothers' weekday screen times and children's weekend screen times, or (2) between fathers' or mothers' weekend screen times and children's weekday screen times, or (3) between children's weekend screen times and BMI (GFI $=0.985$, AGFI $=0.953$, RMSEA $=0.029)$. Recalculation of the model using modified indices reduced the AIC value from 96.351 to 93.030. Thus, the final model demonstrated an acceptable fit (GFI $=0.980, A G F I=0.953$, RMSEA $=0.030$ ). Both fathers' and mothers' weekday screen times were seen to affect children's weekday screen times (from fathers' weekday screen times: 0.136, from mothers' weekday screen times: 0.203), and both fathers' and mothers' weekend screen times were seen to affect children's weekend screen times (from fathers' weekend screen times; 0.139 , from mothers' weekend screen times; 0.271 ). BMI was affected by the children's weekday screen times $(0.117)$. The path coefficient for the indirect effects of mothers' and fathers' screen times on BMI through children's weekday screen times was 0.016 from the fathers' weekday screen times, and 0.024 from the mothers' weekday screen times.

\section{Discussion}

The present study indicated that both fathers' and mothers' weekday screen times had indirect effects on children's weight status through children's weekday screen times among Japanese elementary school children.

There have been no consistent research findings on whether weekday or weekend screen times influences children's BMI. Only children's weekday (and not weekend) screen times were associated with BMI in the present study. A study of adolescents showed no significant correlation between weekday and weekend TV viewing times and BMI [38]; on the other hand, a study of preschool children showed that only 
children's weekend screen times were associated with BMI [18]. The small number of studies evaluating the effects on BMI that separated weekday and weekend screen times may have contributed to the lack of consistent results because whether it is a weekday or a weekend, the total screen time has an impact on BMI. However, to reduce children's screen time, it would be helpful to consider what factors should be addressed on weekdays and weekends separately to adopt those concrete strategies. For example, a study of preschool children [18] reported that there was no association between screen time and BMI on weekends; however, the reason for the association between screen time and BMI on weekdays was that the total amount of time spent in front of a screen on weekdays was low. After all, the students went to school. In this study, the total screen time was also higher on weekdays, which may be one of the reasons for this discrepancy.

Fathers' and mothers' weekday screen times influenced children's weekday screen time, which influenced $\mathrm{BMI}$, and for both weekdays and weekends, the influence of a mother's screen time was stronger than that of a father's screen time. Previous studies on the separate influences of fathers' and mothers' screen times indicated that increased parental TV time was associated with increased TV time in children (father odds ratio $=2.33$ times, mother odds ratio $=2.24$ times) than maternal TV time [24]. The impact of fathers' TV time on children's TV time was found to be stronger than that of mother's TV time in elementary school children (mean age 7.6 years), a similar cohort to the present study [24]. On the other hand, adolescents aged 12-13 years watching TV $\geq 2$ hours per day were associated with mothers who watched TV $\geq 2$ hours per day, but there was no association with fathers' TV time [28]. One of the reasons that these relationships were stronger for mothers than fathers in this study was the fact that children in Japan spend more time with their mothers. In fact, a 2016 survey by the Ministry of Internal Affairs and Communications showed a significant difference in the average time spent with elementary school-aged (over 10 years old) children per day: $4 \mathrm{~h} 52 \mathrm{~min}$ for mothers and $2 \mathrm{~h} 40 \mathrm{~min}$ for fathers [39]. Parents are role models for their children, and by shared time, their behavior could affect a child's behavior. Therefore, maternal modeling might have a stronger effect than paternal modeling on child behavior, as Japanese children spend much time with their mothers.

Moreover, previous studies $[19,27]$ that examined weekday and weekend screen times separately found no association between parents' and children's screen times in a study that did not examine fathers' and mothers' screen times separately [19]. In contrast, the study that examined fathers' and mothers' screen times separately [27] found associations between children's weekday and weekend screen times and both fathers' and mothers' screen times on weekdays and weekends. In a study with at least one parent and a child aged 5-6 years, when parents exceeded $2 \mathrm{~h}$ of TV watching, children were 3.4 times and 4.8 times more likely to spend $\geq 2 \mathrm{~h}$ TV watching during the weekdays and weekend, respectively, if their father exceeded the threshold; the odds were 3.7 for the weekdays and 4.7 for the weekends if their mothers exceeded the threshold [27]. This means that the influence of fathers and mothers may be different on weekdays and weekends. However, in the present study, although both fathers' and mothers' weekday screen times influenced children's weekday screen times and both the fathers' and mothers' weekend screen times influenced children's weekend screen times, the influence of the mothers' screen times was stronger than that of the fathers' screen times on both weekdays and weekends. Japanese children aged 
10-14 years spend an average of 258 min with their mothers and 125 min with their fathers on weekdays, but on Sundays, they spend 411 min with their mothers and 272 min with their fathers; thus, although the children spend some time with their fathers, they spend 1.5 to 2 times longer time with their mothers [40]. Given this difference in Japan, the results of this study, which examined weekday and weekend screen times and paternal and maternal screen times separately, are useful for developing intervention strategies to prevent obesity in Japanese children and reduce screen time.

Regarding the indirect effects on BMI, the strongest path was the influence of maternal weekday screen times on BMI via children's weekday screen times (0.024). On the other hand, fathers' indirect passes were 0.016 . This may be partly due to those, as mentioned earlier, strong maternal commitment to weekday children's screen times, which suggests that mothers' influence should be considered when reducing screen time to improve BMI among Japanese children. Although the study did not examine fathers or mothers separately and was conducted in preschool-aged children, the indirect effect of parental screen time on children's BMI was found only on weekends [18]. In addition, studies that did not examine weekdays and weekends separately examined fathers' and mothers' physical activities separately and showed that the effect of mothers' physical activity on children's physical activity, which affects children's BMI, was significant, but the effect of fathers' physical activity was not [22]. There is a lack of research on the modeling of fathers' and mothers' behaviors on children's behaviors, and of children's behaviors on BMl; further research should be conducted in the future. For example, previous studies have reported efforts to reduce sedentary behavior in children and their parents through interventions targeting mothers and children [41]. There have been efforts to reduce parental sedentary behavior through parent education [42]. In the case of Japanese children, these interventions have been reported. It is expected that these efforts will be applied to improve maternal literacy in particular and reduce children's screen time, thereby improving their anthropometric indices.

Some limitations of this study should be considered. First, the study's cross-sectional nature limits the conclusions that can be drawn about the cause and effect of the observed relationships between parental and children's screen times and anthropometric factors. Second, to estimate screen time, the study relied on self-reported measures that have the potential for error owing to different interpretations of the questions. However, for children, the screen time scale has been used in a national survey of Japanese elementary school children [43], and the parent screen time scale confirmed its reliability and validity [33]. Third, the study respondents were slightly different from the general population. To estimate the representativeness of the participants' responses, the percentage of the population by age group in the present study was compared with data from population estimates [44]. The proportion of boys and girls aged $6-12$ years was $45 \%$ for boys and about $55 \%$ for girls in this study, while the national data was about $51 \%$ for boys and $49 \%$ for girls. Therefore, the essential characteristics of respondents might have been biased. The findings in such a setting may not be sufficiently applicable to the general population. However, the present study population may be considered to have characteristics of the general population. Because the present study randomly selected participants from a registry of residential addresses of each city, which allowed an equal number of potential selects to be obtained from both 
sexes and each age group category between $1^{\text {st }}$ grade and $6^{\text {th }}$ grade. Despite these limitations, few studies have been conducted on this topic in a randomly selected Japanese population, and the findings from the present study will contribute to a greater understanding of parental influences of children's screen time and anthropometric factors, and may also help to develop new strategies and interventions to promote public health and well-being in Japan.

\section{Conclusions}

The present study indicates that both the fathers' and mothers' weekday screen times had indirect effects on children's weight status through children's weekday screen times among Japanese elementary school children, and the influence of the mothers' screen times was stronger than that of the fathers' screen times. The strongest indirect effects were seen by examining the paths of the mothers' weekday screen times via children's screen times to BMI. The total effect of the mothers' weekday screen times on BMI was 0.024 . The present study's findings imply that intervention strategies to reduce screen time should focus on mothers' modeling of children's health status.

\section{Abbreviations}

AGFI, adjusted goodness-of-fit statistic

AIC, Akaike information criterion

BMI, body mass index

GFI, goodness-of-fit statistic

RMSEA, root mean square error of approximation

TV, television

\section{Declarations}

\section{Ethics approval and consent to participate:}

All children, mother, and father signed an informed consent form before answering the questionnaire. The Ethics Committee of Waseda University, Japan, approved the study prior to its commencement (2017245). The present study was conducted in accordance with the principles of the 2013 Declaration of Helsinki.

\section{Availability of data and materials}


The datasets generated and/or analyzed during the current study are not publicly available due because ethical considerations but are available from the corresponding author on reasonable request.

\section{Conflict of interest}

The authors declare that they have no competing interests.

\section{Funding source:}

Kaori Ishii was supported by a Grant-in-Aid for Scientific Research (No. 20K11473) from the Japan Society for the Promotion of Science. The funding sources played no role in data collection and interpretation or decisions about data publication.

\section{Authors' contributions}

KI participated in the design of the study, performed the statistical analyses, and drafted the manuscript. AS and KO conceived the study, participated in its design and coordination, and helped in drafting the manuscript. MJK contributed to the writing and assisted with interpretation of results. All the authors have read and approved the final manuscript.

\section{Acknowledgements:}

We sincerely thank all the study participants.

\section{References}

1. Simmonds M, Burch J, Llewellyn A, Griffiths C, Yang H, Owen C, et al. The use of measures of obesity in childhood for predicting obesity and the development of obesity-related diseases in adulthood: a systematic review and meta-analysis. Health Technol Assess. 2015;19:1-336.

2. Llewellyn A, Simmonds M, Owen CG, Woolacott N. Childhood obesity as a predictor of morbidity in adulthood: a systematic review and meta-analysis. Obes Rev. 2016;17:56-67.

3. Ministry of Education, Culture, Sports, Science, and Technology school health statistics survey; 2019. https://www.mext.go.jp/content/20200325-mxt_chousa01-20200325104819_1-1-1.pdf. Accessed 11 Jan. 2022.

4. Organization for Economic Cooperation and Development. Health at a Glance 2019 OECD Indicators. Accessed 11 Jan. 2022. Paris: OECD Publishing; 2019. https://doi.org/10.1787/4dd50c09-en. 
5. World Health Organization. WHO guidelines on physical activity and sedentary behavior. https://www.who.int/publications/i/item/9789240015128. Accessed 11 Jan. 2022, 2020; 2020.

6. Australian Government Department of Health. Australian 24-hour Movement Guidelines for Children and Young People (5 to 17 years): an Integration of Physical Activity, Sedentary Behavior, and Sleep; 2019. https://www.health.gov.au/resources/publications/australian-24-hour-movement-guidelinesfor-children-5-to-12-years-and-young-people-13-to-17-years-an-integration-of-physical-activitysedentary-behaviour-and-sleep. Accessed 11 Jan. 2022.

7. Tremblay MS, Carson V, Chaput JP, Connor Gorber S, Dinh T, Duggan M, et al. Canadian 24-hour movement guidelines for children and youth: an integration of physical activity, sedentary behaviour, and sleep. Appl Physiol Nutr Metab. 2016. http://www.csep.ca/CMFiles/Guidelines/24hrGlines/Canadian24HourMovementGuidelines2016.pdf. Accessed 11 Jan. 2022;41;Suppl 3:S311-27.

8. Aubert S, Barnes JD, Abdeta C, Abi Nader P, Adeniyi AF, Aguilar-Farias N, et al. Global Matrix 3.0 physical activity report card grades for children and youth: results and analysis from 49 countries. $\mathrm{J}$ Phys Act Health. 2018;15:S251-73.

9. Rideout V, Robb MB. The Common Sense census: media use by tweens and teens. San Francisco, Common Sense Media; 2019.

10. Ishii K, Shibata A, Adachi M, Mano Y, Oka K. School grade and sex differences in domain-specific sedentary behaviors among Japanese elementary school children: a cross-sectional study. BMC Public Health. 2017;17:318.

11. ParticipACTION; 2020. ParticipACTION Report Card on Physical Activity for Children and Youth. https://participaction.cdn.prismic.io/participaction/f6854240-ef7c-448c-ae5c5634c41a0170_2020_Report_Card_Children_and_Youth_Full_Report.pdf. Accessed 11 Jan. 2022.

12. Rhodes RE, Guerrero MD, Vanderloo LM, Barbeau K, Birken CS, Chaput JP, et al. Development of a consensus statement on the role of the family in the physical activity, sedentary, and sleep behaviours of children and youth. Int J Behav Nutr Phys Act. 2020;17:74.

13. Carson V, Janssen I. Associations between factors within the home setting and screen time among children aged 0-5 years: a cross-sectional study. BMC Public Health. 2012;12:539.

14. Carson V, Stearns J, Janssen I. The relationship between parental physical activity and screen time behaviors and the behaviors of their young children. Pediatr Exerc Sci. 2015;27:390-5.

15. Fuemmeler BF, Anderson CB, Mâsse LC. Parent-child relationship of directly measured physical activity. Int J Behav Nutr Phys Act. 2011;8:17.

16. McGuire MT, Hannan PJ, Neumark-Sztainer D, Cossrow NHF, Story M. Parental correlates of physical activity in a racially/ethnically diverse adolescent sample. J Adolesc Health. 2002;30:253-61.

17. Morowatisharifabad MA, Karimi M, Ghorbanzadeh F. Watching television by kids: how much and why? J Educ Health Promot. 2015;4:36.

18. Goncalves WSF, Byrne R, Viana MT, Trost SG. Parental influences on screen time and weight status among preschool children from Brazil: a cross-sectional study. Int J Behav Nutr Phys Act. 
2019;16:27.

19. Hoyos Cillero I, Jago R. Sociodemographic and home environment predictors of screen viewing among Spanish school children. J Public Health (Oxf). 2011;33:392-402.

20. Garriguet D, Colley R, Bushnik T. Parent-child association in physical activity and sedentary behaviour. Health Rep. 2017;28:3-11.

21. De Decker E, Hesketh K, De Craemer M, Hinkley T, De Bourdeaudhuij I, Salmon J, et al. Parental influences on preschoolers' TV viewing time: mediation analyses on Australian and Belgian data. $J$ Phys Act Health. 2015;12:1272-9.

22. Huang H, Wan Mohamed Radzi CW, Salarzadeh Jenatabadi H. H. Family environment and childhood obesity: a new framework with structural equation modeling. Int J Environ Res Public Health. 2017;14:181.

23. Hume C, van der Horst K, Brug J, Salmon J, Oenema A. Understanding the correlates of adolescents' TV viewing: a social ecological approach. Int J Pediatr Obes. 2010;5:161-8.

24. Drenowatz C, Erkelenz N, Wartha O, Brandstetter S, Steinacker JM, URMEL-ICE Study Group. Parental characteristics have a larger effect on children's health behaviour than their body weight. Obes Facts. 2014;7:388-98.

25. Jago R, Sebire SJ, Edwards MJ, Thompson JL. Parental TV viewing, parental self-efficacy, media equipment and TV viewing among preschool children. Eur J Pediatr. 2013;172:1543-5.

26. Jago R, Sebire SJ, Lucas PJ, Turner KM, Bentley GF, Goodred JK, et al. Parental modelling, media equipment and screen-viewing among young children: cross-sectional study. BMJ Open. 2013;3:e002593.

27. Jago R, Thompson JL, Sebire SJ, Wood L, Pool L, Zahra J, et al. Cross-sectional associations between the screen-time of parents and young children: differences by parent and child gender and day of the week. Int J Behav Nutr Phys Act. 2014;11:54.

28. Hardy LL, Baur LA, Garnett SP, Crawford D, Campbell KJ, Shrewsbury VA, et al. Family and home correlates of television viewing in 12-13 year old adolescents: the Nepean study. Int J Behav Nutr Phys Act. 2006;3:24.

29. Latomme J, Van Stappen V, Cardon G, Morgan PJ, Lateva M, Chakarova N, et al. The association between children's and parents' co-TV viewing and their total screen time in six European countries: cross-sectional data from the Feel4diabetes-study. Int J Environ Res Public Health. 2018;15:2599.

30. Xu H, Wen LM, Rissel C. Associations of parental influences with physical activity and screen time among young children: a systematic review. J Obes. 2015;2015:546925.

31. Saris WHM. The assessment and evaluation of daily physical activity in children. A review. Acta Paediatr Scand Suppl. 1985;318:37-48.

32. Manios Y, Kafatos A, Markakis G. Physical activity of 6-year-old children: validation of two proxy reports. Pediatr Exerc Sci. 1998;10:176-88. 
33. Ishii K, Shibata A, Kurita S, Yano S, Inoue S, Sugiyama T, et al. Validity and reliability of Japaneselanguage self-reported measures for assessing adults domain-specific sedentary time. J Epidemiol. 2018;28:149-55.

34. Centers for Disease Control and Prevention. Recommended BMI-for-age cutoffs. https://www.cdc.gov/nccdphp/dnpao/growthcharts/training/bmiage/page4.html. Accessed 11 Jan. 2022.

35. Kline RB. Principle and practice of structural equation modeling. New York: Guilford; 1998.

36. Hu L, Bentler PM. Cutoff criteria for fit indexes in covariance structure analysis: conventional criteria versus new alternatives. Struct Equ Model. 1999;6:1-55.

37. Bozdogan H. Model selection and Akaike's Information Criterion (AIC): the general theory and its analytical extensions. Psychometrika. 1987;52:345-70.

38. Domoff SE, Sutherland E, Yokum S, Gearhardt AN. The association of adolescents' television viewing with Body Mass Index percentile, food addiction, and addictive phone use. Appetite. 2021;157:104990.

39. Ministry of Internal Affairs and Communications 2016 Survey on time use and leisure activities. https://www.stat.go.jp/data/shakai/2016/pdf/gaiyou3.pdf. Accessed 11 Jan. 2022.

40. Ministry of Internal Affairs and Communications 2016 Survey on time use and leisure activities. https://www.e-stat.go.jp/stat-search/file-download?statlnfld=000031655636\&fileKind=0. Accessed 11 Jan. 2022.

41. Tuominen PP, Husu P, Raitanen J, Luoto RM. Rationale and methods for a randomized controlled trial of a movement-to-music video program for decreasing sedentary time among mother-child pairs. BMC Public Health. 2015;15:1016.

42. Nguyen P, Le LK-D, Nguyen D, Gao L, Dunstan DW, Moodie M. The effectiveness of sedentary behaviour interventions on sitting time and screen time in children and adults: an umbrella review of systematic reviews. Int J Behav Nutr Phys Act. 2020;17:117.

43. Japanese Society of School Health Surveillance report on children's health; 2019. https://www.gakkohoken.jp/book/ebook/ebook_R010120/index_h5.html. Accessed 11 Jan. 2022.

44. Statistics Bureau. Ministry of Internal affairs and communications. Natl Census Surv. https://www.estat.go.jp/stat-search/file-download?statlnfld=000031474063\&fileKind=1. Accessed 11 Jan. 2022. 2016.

\section{Figures}




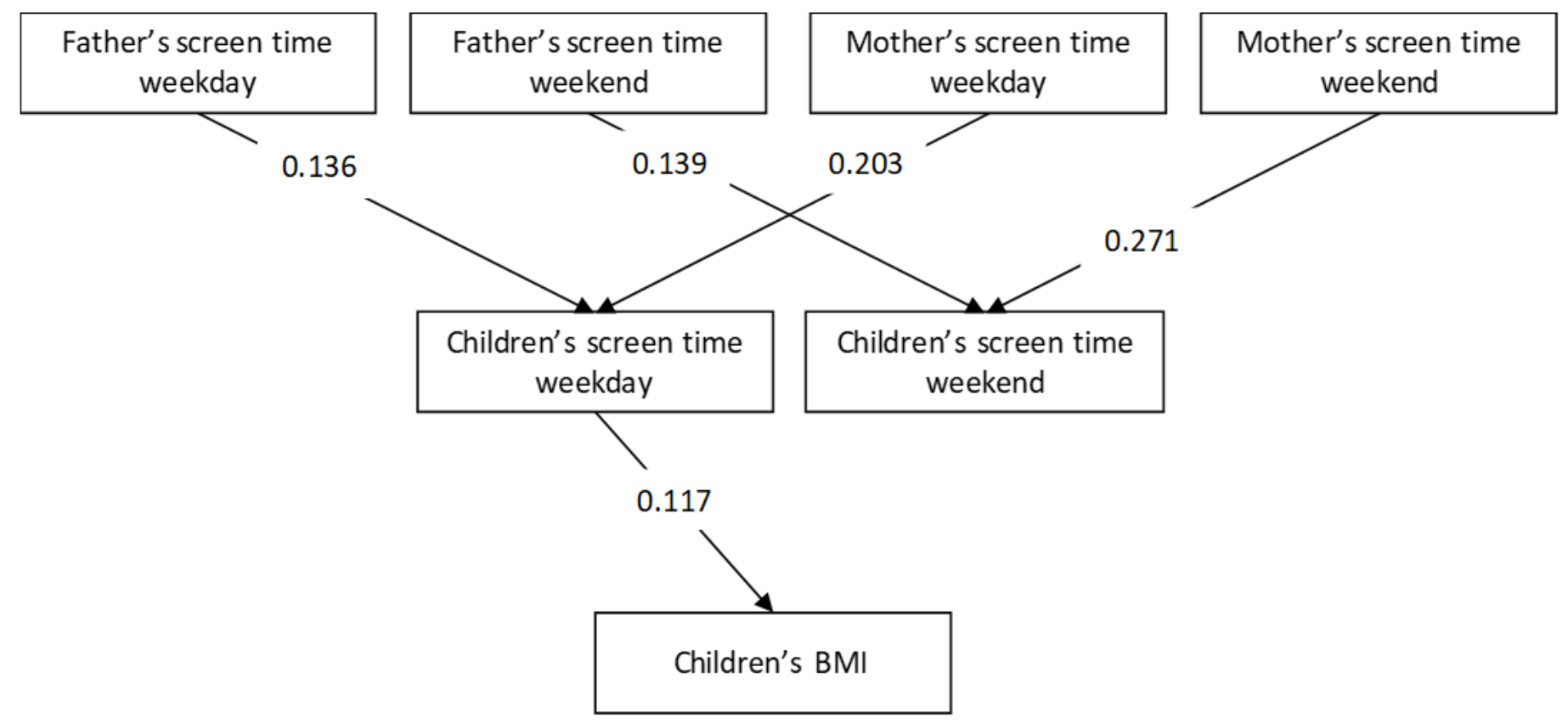

\section{Figure 1}

Direct and indirect effects of parents' and child's screen time behaviors on BMI.

(goodness-of-fit statistic $=0.980$, adjusted goodness-of-fit statistic $=0.953$, root mean square error of approximation $=0.030$ ) Only statistically significant paths are indicated in this figure. All paths are statistically significant at $p<0.05$.

BMI, body mass index 